\title{
Processamento de interrogativas-QU em Português Brasileiro: evidências de eyetracking e EEG
}

\author{
The processing of WH-interrogatives in Brazilian Portuguese: eyetracking and ERP evidences
}

\author{
Fernando Lúcio de Oliveira \\ Marcus Maia \\ Aniela Improta França
}

Universidade Federal do Rio de Janeiro, Rio de Janeiro, RJ, Brasil

$$
\diamond
$$

Resumo: Este artigo trata do processamento de sentenças com interrogativas-QU de sujeito e de objeto em português brasileiro ${ }^{1}(\mathrm{~PB})$. Especificamente, investigou-se a Assimetria SujeitoObjeto nesse tipo de sentença, partindo-se de resultados anteriores com a técnica de leitura automonitorada (OLIVEIRA; MAIA, 2010; OLIVEIRA, 2013). Foram utilizadas as técnicas de rastreamento ocular (eyetracking) e eletroencefalografia (EEG) como ferramentas de diagnóstico do processamento linguístico em tempo real. O objetivo era buscar evidências sobre o modus operandi do parser durante o processamento das funções de sujeito e de objeto em sentenças interrogativas-QU no PB e verificar se há discrepâncias entre as técnicas utilizadas. Os resultados revelam diferenças interessantes, permitindo discernir os níveis de análise representacional, algorítmico e implementacional, na direção da clássica proposta de Marr (1982).

Palavras-chave: Processamento; Assimetria sujeito-objeto; Português brasileiro; Rastreamento ocular; Eletroencefalografia

\begin{abstract}
This article deals with the processing of subject and object WH-sentences of Brazilian Portuguese (BP). Specifically, it investigates the subject/object asymmetry in this type of sentence, following previous results using self-paced reading technique (OLIVEIRA; MAIA, 2010; OLIVEIRA, 2013). Eyetracking and electroencephalography (EEG) techniques were used as diagnostic tools for real-time linguistic processing. The goal was to find evidence of the modus operandi of the parser during the processing of subject and object syntactic functions in Brazilian Portuguese WH-sentences and verify if there are discrepancies between the techniques. The results allow discerning the levels of representational, algorithmic and implementation analysis, in the direction of the classical proposal of Marr (1982).
\end{abstract}

Keywords: Processing; Subject-object asymmetry; Brazilian Portuguese; Eye-tracking; Electroencephalography

\footnotetext{
${ }^{1}$ Os resultados aqui discutidos compõem a tese de doutorado de Oliveira (2017), constante das referências ao final do artigo.
} 


\section{Introdução}

O ponto de partida dos experimentos discutidos neste artigo é a comparação entre frases interrogativas do Português Brasileiro (PB) reportadas na literatura como estando em uma relação sintática de assimetria. Como exemplo, consideremos as frases em (1):

(1) a. Que bolsista _ convidou a caloura no baile?

b. Que bolsista a caloura convidou _ no baile?

As frases em (1) são interrogativas-QU que envolvem a extração de um sintagma-QU2 da posição de sujeito (a) ou da posição de objeto (b). Essas frases apresentam uma diferença não somente pela alteração da ordem de constituintes, como também pela maior distância linear entre o elemento movido Que bolsista e a posição de onde foi deslocado, representada em (1) pelo sinal de sublinhado ( $\_$). Essa desigualdade percebida no nível superficial de uma primeira leitura levanta importantes questões teóricas, entre elas: existiria uma relação assimétrica entre esses sintagmas em níveis mais subjacentes, relacionada a processos cognitivos específicos subjacentes à compreensão de frases no português? Se sim, quais as motivações para tal assimetria? Havendo maior dificuldade de processamento, será sempre para uma das funções (sujeito ou objeto) ou há variação dessa dificuldade? Quais fatores influenciariam tal variação? O estudo da Assimetria Sujeito-Objeto (ASO) está interessado justamente nesses tipos de questões e o presente artigo vai explorá-las e discuti-las à luz de dois experimentos, reportados em Oliveira (2017), tendo sido utilizadas as técnicas de rastreamento ocular (eyetracking) e eletroencefalografia por extração de potenciais elétricos relacionados a evento (EEG/ERP).

Trabalhou-se com a hipótese de que as sentenças interrogativas-QU de sujeito são de modo geral mais fáceis de processar na mente, o que seria refletido em uma integração mais rápida, nas sentenças de sujeito, dos constituintes durante os processos cognitivos em curso. Assim, uma correlação poderia ser feita entre interrogativas-QU de sujeito e tempos menores de leitura, fixação e potenciais elétricos específicos, a depender da técnica utilizada. Tal hipótese tem fundamento na facilidade de processamento do sujeito que tem sido demonstrada por ampla literatura sobre ASO, com sentenças interrogativas e relativas, em estudos de diferentes áreas - aquisição e processamento -, tanto

\footnotetext{
2 Em inglês "WH-phrases", constituintes de natureza pronominal (quem, o que, quanto, quando, como, onde, por que e afins) presentes em sentenças interrogativas. No PB, aparecem tanto movidas para o início da sentença, como em (1a-b), como no lugar onde foram estruturalmente geradas, como em "O calouro convidou quem no baile?".
}

para o português brasileiro e o português europeu (CEREJEIRA, 2009; COSTA et al., 2011; LOBO et al., 2014; OLIVEIRA; MAIA, 2010; OLIVEIRA, 2013; QUAREZEMIN, 2014; ALVES et al., 2015; FRANÇA; GOMES, 2015; inter alia.), quanto para outras línguas (DE VINCENZI, 1991; 1996; GIBSON, 1999; 2000; GIBSON et al., 2005; GOUVÊA, 2005; FANSELOW et al., 2005; HOFMEISTER et al., 2007; KWON et al., 2010; inter alia).

Parte-se do quadro teórico da Teoria da Regência e Ligação (CHOMSKY, 1981), da Teoria do GardenPath (FRAZIER; FODOR, 1978; FRAZIER, 1987) e de trabalhos seminais na área de Psicolinguística Experimental (CLIFTON; FRAZIER, 1989; DE VINCENZI, 1991; 1996) para argumentar que a Assimetria Sujeito-Objeto discutida neste artigo e reportada em trabalhos anteriores (OLIVEIRA; MAIA, 2010; OLIVEIRA, 2013) seja resultado da aplicação de princípios de parsing, como o Princípio do Antecedente Ativo (CLIFTON; FRAZIER, 1989) e o Princípio da Cadeia Mínima (DE VINCENZI, 1991;1996). Além disso, com base no que foi defendido em Oliveira (2017), a ASO poderia estar sob o escopo de atuação de um princípio geral de assimetria, abarcada pela ideia chomskyana de "terceiro fator" ou "necessidade conceptual virtual" (CHOMSKY, 2005). O tema aqui discutido enquadra-se no rol de pesquisas desenvolvidas no âmbito do Laboratório de Psicolinguística Experimental (LAPEX/UFRJ) e do Laboratório de Acesso Sintático da UFRJ (ACESIN/UFRJ).

Serão discutidos no presente artigo dois experimentos reportados em Oliveira (2017), de eyetracking e de EEG (aqui nomeados, respectivamente, como experimento 1 e experimento 2). A intenção em realizá-los foi capturar diferentes medidas sobre o mesmo objeto (interrogativasQU), para compreender melhor o processamento desse tipo de sentenças na mente/cérebro, utilizando diferentes técnicas: a primeira, uma técnica comportamental, bastante utilizada em estudos psicolinguísticos, capaz de capturar os movimentos oculares durante a leitura (reconhecidos como os mais rápidos do corpo humano). A outra (EEG), parte do instrumental da medicina e, desde pelo menos a década de 1980, dos estudos em neurociência da linguagem (cf. KUTAS; HILLYARD, 1980; FRANÇA, 2002, GOMES, 2009; 2014; LAGE, 2013). O experimento 1 testou três tipos de frases (interrogativas-QU de sujeito, interrogativas-QU de objeto e interrogativas-QU in situ) que podiam ser semanticamente congruentes ou não. Basicamente o mesmo desenho experimental e estímulos foram utilizados no experimento 2. Os resultados dos experimentos apontaram para diferentes aspectos do processamento que se deixaram perceber através das diferentes técnicas experimentais. Assim pudemos chegar a uma melhor interlocução entre a sintaxe formal e a área 
experimental. $\mathrm{O}$ trabalho, portanto, reforça a necessidade de se fazer sintaxe experimental cuidadosa no encalço dos melhores ângulos de observação dos problemas linguísticos.

O artigo está organizado em 3 seções. Na seção 1, faremos uma pequena introdução às interrogativas-QU no Português Brasileiro. Na seção 2, abordaremos o fenômeno da Assimetria Sujeito-Objeto e apresentaremos alguns resultados experimentais anteriores utilizando frases do PB. Os experimentos 1 e 2 são discutidos na seção 3 e suas subseções. Reservamos à seção 4 algumas conclusões sobre os resultados obtidos e apontamentos para estudos futuros, seguidos das referências.

\section{Sobre as interrogativas-QU do tipo OSV no Português Brasileiro}

As sentenças interrogativas-QU do Português Brasileiro (PB) possuem uma peculiaridade não encontrada (ou, no mínimo, marginal) no Português Europeu (PE), entre outras línguas: a inversão sintática de uma frase tipicamente Sujeito-Verbo-Objeto (SVO) para uma frase com padrão Objeto-Sujeito-Verbo (OSV). Segundo Eliseu (2008), a ordem de constituintes nas sentenças declarativas comuns e nas interrogativas-QU é diferente em PE, como observado em (2):

(2) a. As minhas amigas sujeito $_{\text {viram }}$ verbo $_{\text {o João }}$ objeto. SVO b. Quem ${ }_{\text {objeto }}$ viram $_{\text {verbo }}$ as minhas amigas sujeito OVS

Em PE, o sujeito tradicionalmente antecede o verbo em declarativas (2a), mas o sucede em interrogativas-QU (2b) - também chamadas interrogativas parciais. Em PB, o mesmo vale para declarativas (3a), mas não para interrogativas-QU (3b), a não ser que a frase esteja fortemente ligada a um contexto específico (3c), o que tenderia a aumentar o seu grau de aceitabilidade:

(3) a. As minhas amigas sujeito $_{\text {viram }}$ verbo o João objeto SVO b. ${ }^{*}$ Quem $_{\text {objeto }}$ viram $_{\text {verbo }}$ as minhas amigas sujeito OVS c. */? Que esmaltes objeto viram verbo as minhas amigas $_{\text {sujeito }}$ ? OVS

Como visto em (3), o PB não aceita normalmente a inversão VS, mas permite a inversão OS (Objeto-Sujeito), que o PE não permitiria:

(4) ${ }^{3}$ Quem $_{\text {objeto }}$ a Maria sujeito $_{\text {encontrou? }}{ }^{v} \mathrm{~PB} / * \mathrm{PE}$

\footnotetext{
3 Os sinais sobrescritos $v \mathrm{e}^{*}$ representam boa formação e agramaticalidade (ou má-formação), respectivamente.
}

Essa característica, a saber, a de apresentar a ordem OSV para interrogativas-QU de objeto oferece uma possibilidade de estudar o fenômeno da Assimetria Sujeito-Objeto sob uma angulação especial, diretamente relacionada à estrutura sintática e à ordem de constituintes da língua. Ela foi objeto de discussão no que o recente artigo de Oliveira (2017b) chamou de Efeito da Lacuna Preenchida na posição de sujeito. Com base nos trabalhos seminais de Crain e Fodor (1985) e de Stowe (1986) e de recentes trabalhos sobre esse efeito (MAIA, 2014a, MAIA, 2014b; MAIA; MOURA; OLIVEIRA, 2014, MAIA, MOURA; SOUZA, 2016), o autor defende que um efeito de processamento ocorre na posição do sujeito interveniente nas interrogativas-QU do tipo OSV, aumentando os tempos de processamento. De modo interessante, esse efeito, evidência experimental obtida com a técnica de leitura automonitorada - self-paced reading, instancia-se do mesmo modo tanto no $\mathrm{PB}$ quanto no PE (cf. OLIVEIRA, 2017b).

Observado o aspecto sintático particular das interrogativas-QU de objeto no $\mathrm{PB}$, decidimos investigar, por meio das técnicas experimentais já comentadas, se a tendência encontrada na literatura psicolinguística (de maior custo cognitivo para o processamento do objeto) se manteria ou se haveria alguma discrepância nas medidas encontradas. Também foi considerado o fato de que recentes trabalhos na área de neurociência da linguagem apresentam tendência que vai de encontro à obtida com testes psicolinguísticos. Isto é, enquanto resultados psicolinguísticos tendem a demonstrar preferência para o processamento do sujeito (HOFMEISTER et al., 2007; OLIVEIRA; MAIA, 2010; KOWN et al., 2010; OLIVEIRA, 2013, 2017; inter alia), resultados de neurociência da linguagem tendem a demonstrar preferência para o objeto (LAGE et al., 2008; GOMES, 2009, 2014; FRANÇA; GOMES, 2015; inter alia.). Procuramos retomar esse tópico na seção 2.1. Antes, cumpre caracterizar o fenômeno da Assimetria SujeitoObjeto em interrogativas-QU do PB.

\section{Assimetria Sujeito-Objeto no Português Brasileiro}

Sejam retomadas as frases apresentadas em (1), da introdução:

(1) a. Que bolsista $t_{i}$ convidou a caloura no baile?

b. Que bolsista ${ }_{i}$ a caloura convidou $t_{i}$ no baile?

Para além da diferença visual e linear já comentadas, o que a Teoria Linguística e a Psicolinguística Experimental nos permitem explicar acerca das frases acima? Ora, o sintagma-QU Que bolsista está em ambas as frases de (1) 
em uma posição estrutural dita A-Barra, não argumental. Isso significa, grosso modo, que naquela posição (no início da sentença) esse sintagma não possui propriedades que permitam interpretá-lo corretamente como um constituinte pertencente à estrutura em formação. Sobre isso, desde o trabalho seminal de Chomsky (1977) sobre "Wh-movement" ("movimento de sintagmas-QU"), há o entendimento na Teoria Linguística de que o movimento é uma regra transformacional que move um sintagma de uma posição a outra, deixando na origem um "nó não preenchido" (unfilled node, p. 84), um "vestígio" do sintagma movido, ambos compartilhando um mesmo índice subscrito. Essa regra poderia, segundo o autor, ser resumida na operação "mova um sintagma-QU para a camada de complementização" (p. 85). Essa camada de complementização, no início da sentença (também chamada Periferia Esquerda) é, então, uma região que abriga elementos que lá estão por resultado de uma regra de movimento sintático, comum nas línguas naturais. Interessante dizer que a posição de origem, vinculada ao elemento movido, é que possui as referidas propriedades para sua correta interpretação dentro da frase. Assim, nada mais natural que nossa mente procure, no momento em que estamos lendo uma frase como (1a) ou (1b), a posição originária para interpretação do sintagma movido (Que bolsista). Essa "busca", que seria feita pelo parser, caracterizado na literatura como um "mecanismo humano de processamento de frases" (cf. MAIA; FINGER, 1995), tem sido alvo de diversas pesquisas e sua investigação tem permitido postular Princípios de Processamento e efeitos resultantes da aplicação desses princípios, tais como o Princípio do Antecedente Ativo (CLIFTON; FRAZIER, 1989) e o Efeito da Lacuna Preenchida (STOWE, 1986).

Feitas essas observações, podemos assumir o postulado de Oliveira (2017a), sobre a Assimetria SujeitoObjeto:

(5) Assimetria Sujeito Objeto (ASO): Dados dois constituintes, em duas frases distintas, um com função de sujeito e outro com função de objeto, a ASO se instancia se uma das frases for agramatical ou mais difícil de processar na mente.

Pela definição de ASO em (5), é suficiente que um dos critérios seja satisfeito para que o fenômeno se instancie: ou agramaticalidade ou maior dificuldade de processamento. A agramaticalidade é uma medida, com base em uma teoria linguística específica, no caso, a Teoria Gerativa, que diz respeito à má-formação de uma frase: ela será agramatical se a gramática de uma língua específica não puder gerá-la de forma natural. Por sua vez, dificuldade de processamento é uma medida sobre o custo cognitivo (em termos de processamento mais lento e maior sobrecarga da memória de trabalho, por exemplo) que uma frase oferece em relação a outra. A ASO definida em (5) ocorrerá, portanto, quando ao menos um desses critérios for satisfeito.

Sobre a agramaticalidade de que (5) trata, podemos observar um caso do inglês, relacionado ao movimento longo de sintagmas-QU. Chomsky (1977) argumenta em favor de uma regra geral que regula o movimento de estruturas para a Periferia Esquerda da sentença. Ele propõe que alguns tipos de sintagmas (incluindo os sintagmas-QU) com um traço formal [+WH] devam ser movidos para a camada de complementação da estrutura. Esse movimento é regulado por algumas propriedades sintáticas, que podem se instanciar nas diferentes línguas naturais na forma de parâmetros variáveis. Sobre isso, o trabalho clássico de Ross (1967) elenca uma série de configurações estruturais que bloqueiam o movimento de sintagmas-QU. Por exemplo, as frases em (6) parecem malformadas no português brasileiro:

(6) a. *Que livro o aluno encontrou o professor que escreveu_?

b. *Por que o aluno perguntou que o professor escreveu um livro ?

c. *Que livro comprar custa caro?

A frase (6a) é agramatical porque o sintagmaQU não pode ser extraído de dentro de uma oração relativa. Já em (6b) a extração desse mesmo sintagma de dentro de uma oração factiva também é agramatical. A agramaticalidade ocorre, ainda, se o sintagma-QU é extraído de um sujeito sentencial (6c). Ross chama esses e outros contextos sintáticos de "ilhas", que impõem restrições ao movimento de sintagmas-QU. Chomsky (1973) reúne propriedades comuns às construções de ilha e postula a Condição de Subjacência (CS), argumentando que o movimento de sintagmas-QU não pode atravessar mais de um nó fronteira, sendo esses nós $\mathrm{SN}$ e $\mathrm{S}$ (DP e IP, em termos mais atuais). A Condição de Subjacência é parametrizada, posteriormente, por Rizzi (1982). Ele demonstra que os nós fronteiras relevantes para o italiano seriam SN e S' (DP e CP). Quanto a isso, o português brasileiro parece ser semelhante ao italiano, como se observa em (7):

(7) a. Que livro [DP o professor escreveu__ ] mas ninguém leu?

$\mathrm{b} *$ Que livro [DP o professor [CP que escreveu __ ] ] ninguém leu?

A Condição de Subjacência (CS) atuaria, então, sobre contextos sintáticos como $(7 \mathrm{a}, \mathrm{b})$ e permitiria $(\mathrm{a})$, 
pois o movimento atravessaria apenas um nó fronteira, o DP. Entretanto, o movimento em (b) seria bloqueado, já que a frase contém um sintagma nominal complexo formado pelo DP cujo núcleo é professor, relativizado por que escreveu. Assim, na frase (b), o sintagma-QU precisa atravessar dois nós fronteiras: o $\mathrm{CP}$ e o DP, o que viola a Condição de Subjacência e gera agramaticalidade. Os exemplos em (7) servem para compreender a CS como um princípio influente na Assimetria Sujeito Objeto, no sentido de gerar agramaticalidade em estruturas com extração de objeto.

Quanto à maior dificuldade de processamento, também prevista no postulado (5), trata-se de um efeito observável por meio do uso de diferentes técnicas experimentais e geralmente refletido em médias temporais maiores: tempo de leitura (leitura automonitorada), tempo de fixação (rastreamento ocular), tempo de reconhecimento (priming). Esses tempos são compreendidos como diretamente proporcionais à dificuldade de processamento da estrutura: tempos médios maiores indicam custo cognitivo maior. Portanto, em frases como as apresentadas em (1) neste artigo, haveria maior custo de processamento para uma delas em relação à outra. A literatura aponta que frases como (1a) costumam ser mais facilmente processadas do que (1b). Apesar disso, resultados com a técnica de eletroencefalografia têm colocado novos desafios à interpretação dos resultados obtidos, como será discutido nas seções seguintes.

\subsection{Resultados Anteriores}

Oliveira \& Maia (2010) discutem os resultados de um experimento de leitura automonitorada com interrogativas-QU do PB semelhantes às de (8):

(8) a. Quem / encontrou / o Lúcio / na cidade / ontem?

b. Quem / o Lúcio / encontrou / na cidade / ontem?

Os resultados revelaram que os tempos médios de leitura dos três primeiros segmentos (divididos simbolicamente pelas barras) foram significativamente maiores para as interrogativas-QU de objeto $(8 \mathrm{~b})$ do que para as suas contrapartes de sujeito (8a), achado que indicou a instanciação da ASO no PB e serviu de base para a realização de novos experimentos.

Nessa mesma linha, Oliveira (2013) discute os resultados de três experimentos de leitura automonitorada, dos quais reportaremos aqui apenas os dois primeiros. No experimento (1), o autor trabalhou com frases como as exemplificadas em (9):

(9) a. Quem conheceu o Pedro na escola do bairro? b. Quem o Pedro conheceu na escola do bairro?
Os resultados basicamente replicaram os achados de Oliveira e Maia (2010): frases em que o sintagma-QU foi extraído da posição de objeto (como 9b) capturaram tempos médios de leitura significativamente maiores que os das frases com extração de sujeito (como 9a). Em um segundo experimento discutido em Oliveira (2013), utilizando a mesma técnica, o autor manipulou, além do tipo de extração (sujeito/objeto), variável já testada em outros experimentos, a inclusão de um sintagma preposicional entre o sintagma-QU movido e o verbo. Essa nova variável serviria para testar no $\mathrm{PB}$ frases semelhantes às que Hofmeister et al. (2007) usaram em testes de julgamento de aceitabilidade no inglês:

(10) a. Que homem / roubou / o José / no parque?

b. Que homem / no parque florestal da cidade / roubou/ o José?

c. Que homem / roubou / o José / no parque florestal da cidade?

d. Que homem / o José / roubou /no parque?

e. Que homem / no parque florestal da cidade / o José / roubou?

f. Que homem / o José / roubou / no parque florestal da cidade?

Tomado como segmento crítico o José, destacado nas frases acima, foram medidos os tempos médios de leitura e submetidos a análises estatísticas. Os resultados revelaram tendência semelhante à dos outros experimentos reportados aqui: instanciação da Assimetria SujeitoObjeto, com maior custo cognitivo para o processamento das frases de objeto $(10 \mathrm{~d}, \mathrm{e}, \mathrm{f})$ do que para as de sujeito $(10 \mathrm{a}, \mathrm{b}, \mathrm{c})$. Além disso, a distância linear foi influente no processamento dessas estruturas, visto que as frases em que o sintagma preposicional estava intervindo entre o sintagma-QU e o verbo $(10 \mathrm{~b}, \mathrm{e})$ apresentaram tempos maiores de processamento.

Apesar da aparente unanimidade, o estudo da Assimetria Sujeito-Objeto vem, nos últimos anos, sendo alvo de discussões sobre as discrepâncias encontradas na literatura, sobretudo quando se consideram resultados obtidos no campo das pesquisas em neurociência da linguagem, tais como os trabalhos de Lage et al. (2008), França e Gomes (2015) e França, Cagy e Infantosi (2017). França e Gomes (2015) encontraram maiores latências para o sujeito em declarativas comuns com inversão de papéis temáticos, do tipo em (11b). As autoras realizaram dois experimentos de EEG com frases do inglês americano, dos quais vamos reportar o primeiro. As frases utilizadas são equivalentes às de (11):

(11) a. O delegado prendeu o ladrão em flagrante. b. O ladrão prendeu o delegado em flagrante. c. O delegado prendeu a alma em flagrante. 
O argumento é o de que isso seria um efeito do custo de integração do argumento externo (sujeito) após a concatenação entre o verbo e seu complemento, relação local sintaticamente primária e, logo, anterior no curso temporal do processamento. Assim concebese naquele artigo que um verbo como prendeu seria primeiramente concatenado a seu argumento interno o delegado. Somente então o complexo [verbo+complemento] seria concatenado ao argumento externo o ladrão, que funcionaria como sujeito. Então, a incompatibilidade (ou, no mínimo, implausibilidade) semântica da integração de o sujeito o ladrão ao predicado prendeu o delegado levaria a um alto custo de processamento tardio, relacionado ao achado do P600. As autoras assumem que em frases como (11) sintagmas nominais na posição de sujeito (como $O$ delegado) "seriam processados como uma estrutura atemática, que ficaria mantida na memória do leitor até que o verbo e o objeto, como 'prendeu o ladrão' fossem processados" (p. 367). Os resultados apontaram um N400 significativo na comparação entre a condição controle (11a) e a incongruente (11c). O P600 só foi encontrado em relação a (11b), devido ao estranhamento semântico provocado pela inversão de papéis temáticos percebida na altura em que o sujeito seria integrado à sentença que está sendo analisada: não se supõe que um ladrão prenda um delegado, mas sim o contrário.

Outro trabalho no âmbito da neurociência da linguagem que utiliza a técnica de eletroencefalografia para estudar a integração de estruturas de sujeito, é o artigo de França, Cagy e Infantosi (2017). Nele, os autores investigam o mecanismo da referencialidade por meio de duas condições: um sintagma nominal não específico na posição de sujeito e um sintagma nominal que denota tipo, influenciado por um contexto de Conhecimento do Mundo:

(12) a. O Maurício extraiu o dente facilmente.

b. O Maurício extraiu o trovão facilmente.

c. O dentista extraiu o dente facilmente.

d. O dentista extraiu o trovão facilmente.

Nos exemplos em (12), todas as condições são do tipo SVO [Sujeito-[Verbo-Objeto]], com essencialmente os mesmos itens. Na posição prototípica de sujeito, um nome sem referência específica (Maurício) é comparado a um nome que denota tipo (Dentista). Na posição de objeto, o contraste é entre um nome semanticamente congruente (dente) e um incongruente (trovão). $\mathrm{O}$ artigo explorou se Maurício e dentista seriam processados do mesmo modo nas frases ou se o conteúdo semântico de referencialidade desses nomes seria acessado pelo parser. Além disso, previu-se que a integração do objeto incongruente trovão produziria uma reação cortical em forma de um N400 de grande amplitude. As previsões confirmaram-se nos resultados: um N400 de grande amplitude é gerado nas condições com objeto incongruente, tanto nas sentenças de controle (12b) quanto nas sentenças relacionadas ao conhecimento de mundo sobre a referência do nome (12d). Nestas (12d), além do N400, um P600 também foi observado, algo interpretado pelos autores como evidência de que "componentes semânticos e pragmáticos do sintagma nominal em posição de sujeito nas condições WK $[12 \mathrm{c}, \mathrm{d}]$ são totalmente digeridos somente ao final da computação da sentença" (p. 22). Ademais, comparandose o N400 encontrado nas sentenças de controle $(12 \mathrm{a}, \mathrm{b})$ ao encontrado em $12 \mathrm{c}$, d, esse ERP foi eliciado mais cedo nestas $(\mathrm{c}, \mathrm{d})$ do que naquelas $(\mathrm{a}, \mathrm{b})$.

Como observado por Oliveira (2017), os resultados de França \& Gomes (2015) e França, Cagy e Infantosi (2017) foram obtidos estudando-se frases declarativas e não interrogativas, como as de Oliveira e Maia (2010), Oliveira (2013) e as de alguns trabalhos reportados na introdução deste artigo. E existe uma diferença crucial entre declarativas e interrogativas: as interrogativas envolvem o deslocamento de um sintagma-QU para uma posição não argumental enquanto as declarativas não. Dada essa particularidade, o processamento de interrogativas-QU obedece a um Princípio de Processamento estabelecido na literatura psicolinguística desde o final da década de 1980, o Princípio do Antecedente Ativo (CLIFTON; FRAZIER, 1989). Ele prediz que, ao encontrar um sintagma-QU em uma posição A-barra, o parser dispara uma busca por uma posição onde esse constituinte possa ser corretamente interpretado, o que leva a uma série de efeitos de processamento, entre os quais o já mencionado Efeito da Lacuna Preenchida.

Esse conjunto de resultados colocou de modo imperativo um desafio: testar declarativas e interrogativasQU do PB por meio de novos testes, com diferentes técnicas, mais refinadas que a de leitura automonitorada, buscando explicar as diferenças encontradas até aqui. Para isso, discutimos na seção 3, a seguir, os procedimentos metodológicos resultados de dois experimentos: um de rastreamento ocular e outro de eletroencefalografia.

\section{Experimentos}

Nesta seção, apresentamos os procedimentos metodológicos e discutimos os resultados de dois experimentos reportados em Oliveira (2017), buscando utilizá-los para explicar as discrepâncias comentadas na seção 2.2, acerca das diferentes técnicas utilizadas no estudo do mesmo objeto. 


\subsection{Rastreamento Ocular com frases do Português Brasileiro}

Este experimento investigou o fenômeno da Assimetria Sujeito-Objeto em frases do Português brasileiro utilizando-se a técnica de eyetracking (rastreamento ocular), com julgamento de pergunta interpretativa, com o objetivo de investigar a relação entre função sintática, congruência semântica e dificuldade de processamento em frases interrogativas-QU de sujeito e de objeto do português brasileiro. O equipamento utilizado foi o Eyelink $1000^{\mathrm{TM}}$, com câmera de alta precisão (até $2000 \mathrm{Hertz}(\mathrm{Hz})$ ) e 1.4 milissegundos (ms) de velocidade no acesso ao estímulo.

\subsubsection{Variáveis Independentes}

Preparou-se um design $3 \times 2$ em que a variável tipo de frase, com três níveis (interrogativa-QU de sujeito, interrogativa-QU de objeto e interrogativa local ou in situ) cruza com a variável congruência semântica, com dois níveis (congruente, incongruente). Cada nível foi rotulado com um código para fins de identificação na etapa de análise dos resultados: interrogativa-QU de sujeito [S], interrogativa-QU de objeto [O] e interrogativa local [L] ou in situ, congruente [C], incongruente [I], gerando as combinações $\mathrm{SC}, \mathrm{SI}, \mathrm{OC}, \mathrm{OI}$, LC e LI.

\subsubsection{Variáveis Dependentes}

Dentre as várias medidas que o aparelho de rastreamento ocular permite capturar, foi utilizada a duração total da fixação (total fixation duration), em milissegundos, nas regiões de interesse (segmentos 1, 2 e 3 , como no experimento 2 ), por ser uma medida global da atenção, do interesse e do custo de processamento durante a leitura. A região de interesse é a área específica do estímulo onde se espera que os efeitos de processamento sejam verificados.

\subsubsection{Condições Experimentais}

Cruzando as variáveis independentes, obteve-se um conjunto de 6 condições, cada qual iniciando uma versão do experimento, de acordo com o esquema de quadrado latino (os participantes viram todas as condições, mas não os mesmos itens/frases de cada condição). Essas condições estão codificadas e distribuídas de acordo com o Quadro 1, abaixo. As perguntas incidiam sobre o agente da ação verbal em todas as condições e as posições das respostas foram manipuladas de modo que $50 \%$ das respostas certas estivessem à esquerda e 50\%, à direita, para evitar a influência, nas respostas, de fatores como a forma de apresentação dos itens.

\subsubsection{Materiais}

Utilizamos, ao todo, 144 frases experimentais, distribuídas em 6 versões, sendo 24 frases experimentais por versão. Além disso, foram incluídas 48 frases distrativas, comuns a todas as versões. Cada versão do experimento contou, portanto, com 72 frases (24 experimentais +48 distrativas).

\subsubsection{Procedimento}

Primeiramente, cada voluntário assinou um Termo de Consentimento Livre e Esclarecido (TCLE). Depois, participou de uma atividade de prática, com a instrução do pesquisador. Assim que o sujeito se declarava pronto para iniciar o experimento, ele pressionava a barra de espaços e iniciava a tarefa experimental. A tarefa experimental consistiu na apresentação do estímulo por 5 segundos (tempo padronizado pelo pesquisador) na tela do computador. Ao final, uma pergunta era feita, incidindo sobre a ação verbal. Então o participante precisava escolher a resposta que julgasse correta, olhando fixamente para ela. Depois, bastava pressionar a barra de espaços para reiniciar a tarefa, procedendo desse modo até o fim do experimento ser anunciado na tela.

Quadro 1. Exemplos de condições experimentais.

\begin{tabular}{|c|c|c|c|c|c|c|c|}
\hline Código & Seg 1 & Seg 2 & Seg 3 & Seg 4 & Pergunta & S \\
\hline SC & Que bebida & aqueceu & o turista & no inverno? & Quem aqueceu? & a bebida & o turista \\
\hline OC & Que bebida & o turista & aqueceu & no inverno? & Quem aqueceu? & o turista & a bebida \\
\hline SI & Que galáxia & aqueceu & o turista & no inverno? & Quem aqueceu? & a galáxia & o turista \\
\hline OI & Que galáxia & o turista & aqueceu & no inverno? & Quem aqueceu? & o turista & a galáxia \\
\hline LC & O turista & aqueceu & que bebida & no inverno? & Quem aqueceu? & o turista & a bebida \\
\hline LI & O turista & aqueceu & que galáxia & no inverno? & Quem aqueceu? & o turista \\
\hline
\end{tabular}

SC (interrogativa-QU de sujeito congruente); OC (interrogativa-QU de objeto congruente); SI (interrogativa-QU de sujeito incongruente) OI (interrogativa-QU de objeto incongruente); LC (interrogativa local de objeto congruente); LI (interrogativa local de objeto incongruente). 
O participante era acomodado diante do computador, sentado em uma cadeira e posicionado em um suporte que serve para manter a cabeça em repouso. Ao posicionar o sujeito, o rastreador automaticamente detectava a posição da pupila do indivíduo. Eram iniciados, então, os procedimentos de configuração da câmera (foco, posição, distância adequada em torno de $70 \mathrm{~cm}$ ) e calibração (sincronizar a câmera do rastreador com os movimentos do olho do participante para regiões específicas, préconfiguradas como diferentes pontos na tela, geralmente nove). Concluída a configuração e a calibração, era necessário validar/checar as fixações oculares capturadas. Então, o pesquisador submetia o voluntário a uma tarefa prática, para verificar se ele compreendeu como deveria realizar as etapas, depois iniciava a coleta dos dados, que durava em média 30 minutos.

\subsubsection{Participantes}

A coleta dos dados ocorreu no Laboratório de Psicolinguística Experimental (LAPEX/UFRJ). Foram testados 24 participantes, alunos de graduação em Letras da UFRJ. Cada um leu 4 itens experimentais de cada condição, totalizando 96 dados por condição. Os participantes foram testados isoladamente, seguindo as instruções do pesquisador, também presente na sala durante a tarefa, com idade média de 21 anos, sendo 16 do sexo feminino e 8 do sexo masculino.

\subsubsection{Hipóteses e Previsões}

Trabalhamos com a hipótese inicial de que o processamento visual da compreensão de frases interrogativas-QU de sujeito é menos complexo que o das suas contrapartes de objeto. Diversos resultados utilizando a mesma técnica já foram reportados como evidência da Assimetria Sujeito-Objeto. Alves et al. (2015), por exemplo, utilizaram a técnica de rastreamento ocular para testar frases clivadas de sujeito e de objeto. Os resultados sugeriram, entre outras coisas, um menor custo de processamento para sentenças clivadas de sujeito em relação às de objeto. Alguns trabalhos sobre o português tratam de interrogativas-QU, mas não especificamente sobre o tema da Assimetria Sujeito-Objeto (por exemplo, o estudo sobre aspectos prosódicos do QU in situ, BARILE; MAIA, 2008) ou tratam apenas do processamento de interrogativas-QU de objeto (MAIA, 2014a, MAIA, 2014b, MAIA; MOURA; OLIVEIRA, 2014; MAIA; MOURA; SOUZA, 2016) ou, ainda, tratam do tema, mas no campo da aquisição e não do processamento (por exemplo, o artigo de CEREJEIRA, 2009, sobre aquisição de interrogativas de sujeito e de objeto). Por isso, os experimentos discutidos nesta seção buscam preencher essa importante lacuna.

As previsões do Experimento 1 aqui reportado incluíam tempos totais de fixação menores para as interrogativas QU de sujeito (SC e $\mathrm{SI}$ ) em relação às de objeto (OC e OI). Além disso, as condições com QU in situ (LC e LI) eram esperadas como mais fáceis de processar do que as condições com QU movido (SC, OC, SI, OI), pois estas envolvem o deslocamento de um constituinte que resulta na alteração da ordem linear e aquelas não. Assim, previam-se menores tempos de fixação para aquelas duas condições (LC e LI) comparadas às suas correspondentes OC e OI. Explorou-se também a influência do fator "congruência semântica" (isso significa que a congruência semântica foi inserida de modo exploratório no conjunto de variáveis, para permitir uma base de comparação com um futuro experimento, utilizando a técnica de EEG).

\subsubsection{Resultados}

Os dados foram tratados estatisticamente, para evitar o máximo possível a interferência de ruídos no que foi capturado (piscadas, movimentos muito longos ou abruptos, falhas de rastreamento, entre outras) no EyeDoctor $^{\mathrm{TM}}$ e os resultados foram extraídos para análise por meio do EyeDry ${ }^{\mathrm{TM}}$. O Microsoft Excel 2017 ${ }^{\mathrm{TM}}$ foi usado para a crítica de dados (trimming de outliers). Apresentamos a seguir o tempo total de fixação para o sintagma nominal e o sintagma-QU. O Gráfico 1 ilustra as médias encontradas para o sintagma nominal (nos exemplos do Quadro 1, o turista):

Gráfico 1. Tempo total de fixação no sintagma nominal

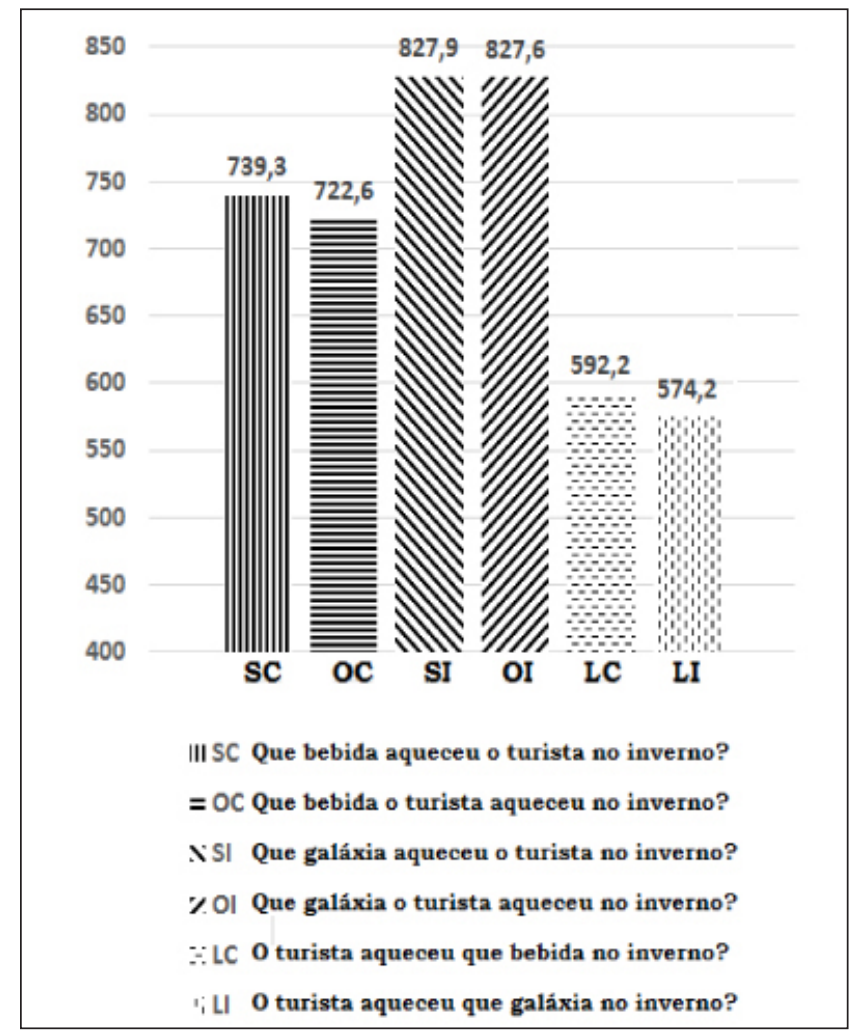


A ANOVA revelou diferenças altamente significativas para o fator tipo de frase (QU-sujeito/QUobjeto/QU-in-situ): $\mathrm{F}(2,190)=413 p<0,000001^{* *}$; para congruência semântica (congruente/incongruente): $\mathrm{F}(1,95)=108 p<0,000001^{* *}$ e para a interação entre os fatores: $\mathrm{F}(2,190)=53,5 p<0,000001^{* *}$. O Teste T revelou diferenças estatisticamente significativas para várias comparações, dentre elas: $\mathrm{SC} \times \mathrm{SI}\left[t(95)=8,06 p<0,0001^{*}\right]$; $\mathrm{SC} \times \mathrm{OI}[t(95)=7,67 p<0,0001 *] ; \mathrm{OC} \times \mathrm{LC}[t(95)=10,08$ $p<0,0001 *]$; OC $\times$ OI $[t(95)=9,03 p<0,0001 *]$.

Apresentamos também as médias dos tempos totais de fixação para o segmento correspondente ao sintagma-QU (nos exemplos do Quadro 1, que bebida e que galáxia):

Gráfico 2. Tempo total de fixação no sintagma-QU

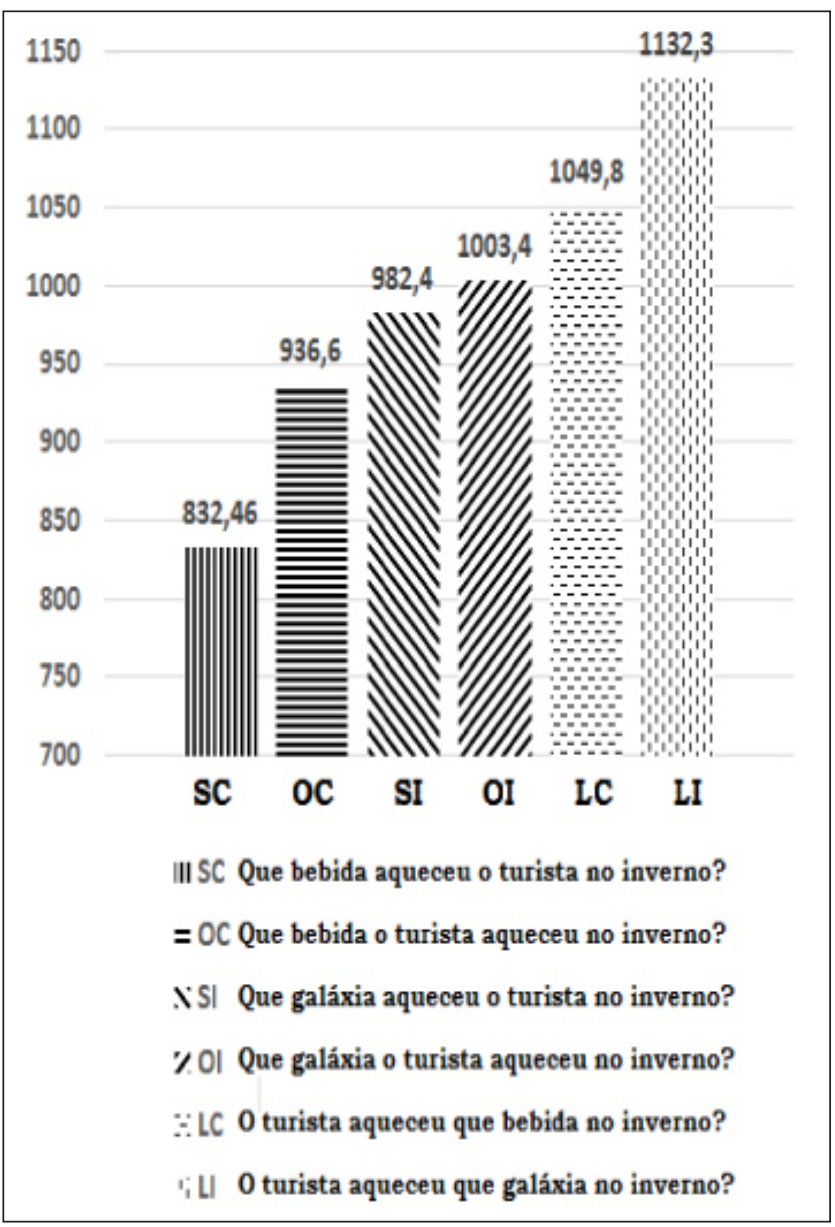

A ANOVA para as médias do Gráfico 2 demonstrou resultados estatisticamente significantes: tipo de frase (QU-sujeito/QU-objeto/QU-in-situ): $\mathrm{F}(2,190)=9,17$ $\mathrm{p}<0,000158^{* *}$; congruência semântica (congruente/ incongruente): $\mathrm{F}(1,95)=8,35 p<0,004774 * *$; interação entre fatores: $\mathrm{F}(2,190)=0,789 p<0,455957 \mathrm{~ns}$. O Teste $\mathrm{T}$ mostrou significância estatística para as comparações:
$\mathrm{SC} \times \operatorname{LC}\left[t(95)=4,07 p<0,0001^{* *}\right] ; \mathrm{SI} \times \operatorname{LI}[\mathrm{t}(95)=2,42 p<$ $0,0174 *]$.

\subsubsection{Discussão}

No Gráfico 1, o contraste das condições OC (Que bebida $o$ turista aqueceu $-722,6 \mathrm{~ms}$ ) $\times \mathrm{LC}$ (o turista aqueceu que bebida - 592,2ms) mostra que o sujeito em posição canônica (o turista em LC) oferece menos custo ao processamento do que o sujeito interveniente entre um sintagma-QU movido e um verbo (o turista em OC), $t(95)=10,08 p<0,0001^{* *}$. Algo semelhante ocorre na comparação OI $[827,6 \mathrm{~ms}] \times \operatorname{LI}[574,2 \mathrm{~ms}]$, $t(95)=47,24 p<0,0001 * *$. Esse resultado argumenta em favor de que o parser é sensível a elementos estruturais intervenientes, como prediz o Princípio da Cadeia Mínima (DE VINCENZI, 1991,1996) e de que o efeito é percebido já no segundo segmento também em tarefas de rastreamento ocular. Com relação à congruência semântica, as comparações $\mathrm{SC} \times \mathrm{SI}$ e $\mathrm{OC} \times \mathrm{OI}$, com diferenças estatisticamente significativas, revelam que os efeitos de processamento em frases que envolvem incongruências se daria no terceiro segmento (o turista). Nesse caso, uma interpretação possível é a de que a leitura processada por um parser serial, incrementacional, cego à introspecção, a incongruência semântica não seria detectada e uma espécie de efeito garden-path ocorreria na posição do objeto do verbo (o turista), no sentido de que a estrutura formada até então teria de ser reanalisada, gerando tempos significativamente maiores nas frases incongruentes. Outra possibilidade é considerar que as operações realizadas pelo parser na mente humana seguem o curso bottom-up, semelhantemente ao que ocorreria com sentenças declarativas (cf. FRANÇA; GOMES, 2015; FRANÇA; CAGY; INFANTOSI, 2017) e que o efeito encontrado nessa posição é devido ao custo de integração do argumento externo (nesse caso, o SN sujeito) à estrutura.

Para o Gráfico 2 (região do sintagma-QU), algumas comparações relevantes são: SC[832,46ms]× LC[1049,8ms], $t(95)=4,07 p<0,0001 * * ; \operatorname{SI}[982,4 \mathrm{~ms}] \times$ LI[1132,3ms], $t(95)=2,42 p<0,0174 *$, o que mostra que o sintagma-QU in situ no experimento 1 demonstrou-se mais difícil de processar. Essa diferença indica que uma frase como "O turista aqueceu que bebida no inverno?", com sintagma-QU in situ, seria menos aceitável ou menos natural do que uma interrogativa com sintagmaQU movido. Esse resultado, originalmente fora das previsões, pode ser atribuído à natureza dos estímulos utilizados: eles eram visuais/lidos e não sonoros/ouvidos. Parece plausível pensar que, se os estímulos envolvessem algum tipo de pista prosódica, os resultados poderiam ser diferentes, o que não deixa de constituir uma possibilidade futura para novas investigações. 
Os resultados do experimento 1 serviram como base para a elaboração de um segundo teste, utilizando-se a técnica de eletroencefalografia por extração de potenciais elétricos relacionados a eventos linguísticos (EEG), discutido na seção 3.2.

\subsection{Eletroencefalografia por extração de potenciais elétricos (EEG)}

Apresentam-se nesta seção os procedimentos metodológicos e os resultados obtidos com um teste de EEG para frases do português brasileiro. Um dos objetivos principais foi verificar se a leitura do sintagma nominal causaria efeitos de processamento em termos de ERPs, de modo similar ao experimento 1. Explorou-se, também, a diferença sintagma-QU in situ $\times$ sintagma-QU movido em busca de ERPs que caracterizem a assimetria entre essas estruturas e buscou-se verificar se a tendência de efeitos atuantes sobre interrogativas-QU de objeto seria novamente verificada. O design foi idêntico ao do experimento de rastreamento ocular discutido na seção 3.1.

\subsubsection{Variáveis Independentes}

Cruzaram-se 2 variáveis ${ }^{4}$, uma com três níveis: tipo de frase (interrogativa-QU sujeito [S] / interrogativa-QU objeto [O] / interrogativa-QU local ou in situ [L] e outra com dois níveis: congruência semântica (congruente [C] / incongruente [I]) num design $3 \times 2$.

\subsubsection{Variáveis Dependentes}

As variáveis dependentes foram ERPs de integração do sujeito e do objeto à estrutura (P600 e N400).

\subsubsection{Condições Experimentais}

Do cruzamento das variáveis independentes, foram codificadas 6 condições experimentais, exemplificadas Quadro 2, abaixo. Como se pode observar, no experi- mento 1, a pergunta focalizava o agente da ação verbal e, no experimento 2 , o sentido da frase. Isso porque o foco da pergunta interpretativa era diferente: no primeiro experimento, buscava-se compreender como o participante processava a grade argumental do verbo em sentenças com interrogativas-QU e se o modo como ele o fazia influenciava na fase off-line da tarefa. Já no segundo, a intenção era verificar se a incongruência semântica comumente detectada na fase on-line perseverava de algum modo até a fase final (off-line).

\subsubsection{Materiais}

O experimento foi dividido em 6 versões. Cada uma contou com 36 frases experimentais e mais 72 frases distrativas, comuns em todas as versões, num total de 108 frases por versão, distribuídas de em esquema de quadrado latino.

\subsubsection{Participantes}

38 participantes realizaram a tarefa experimental (6 por versão +2 extras). Desses, 22 apresentaram sinais aproveitáveis para fins de análise estatística. Todos eles, recrutados das turmas de graduação em Letras e em Fonoaudiologia da UFRJ, foram testados isoladamente na sala D-103, do Laboratório de Acesso Sintático (ACESIN/ UFRJ). No início de cada coleta, foi feita uma breve prática do experimento e o participante foi orientado a assinar um Termo de Consentimento Livre e Esclarecido, documento que explica informações sobre a pesquisa, o pesquisador, a ética envolvida, entre outras.

\subsubsection{Procedimento}

Utilizamos o E-Prime ${ }^{\mathrm{TM}}$, versão 2.0, da Psychology Software Tools ${ }^{\mathrm{TM}}$ para programar uma tarefa experimental aplicada enquanto um aparelho de EEG da BrainVision ${ }^{\mathrm{TM}}$ de 32 canais ativos media a atividade elétrica no córtex cerebral de cada voluntário. Os eletrodos são ajustados

Quadro 2. Exemplos de condições experimentais.

\begin{tabular}{|c|c|c|c|c|l|c|c|}
\hline Código & Seg 1 & Seg 2 & Seg 3 & Seg 4 & Pergunta & S & L \\
\hline SC & Que bebida & aqueceu & o turista & no inverno? & Essa frase faz sentido? & sim & não \\
\hline OC & Que bebida & o turista & aqueceu & no inverno? & Essa frase faz sentido? & $\operatorname{sim}$ & não \\
\hline SI & Que galáxia & aqueceu & o turista & no inverno? & Essa frase faz sentido? & $\operatorname{sim}$ & não \\
\hline OI & Que galáxia & o turista & aqueceu & no inverno? & Essa frase faz sentido? & $\operatorname{sim}$ & não \\
\hline LC & O turista & aqueceu & que bebida & no inverno? & Essa frase faz sentido? & $\operatorname{sim}$ & não \\
\hline LI & O turista & aqueceu & que galáxia & no inverno? & Essa frase faz sentido? & $\operatorname{sim}$ & não \\
\hline
\end{tabular}

SC (interrogativa-QU de sujeito congruente); OC (interrogativa-QU de objeto congruente); SI (interrogativa-QU de sujeito incongruente); OI (interrogativa-QU de objeto incongruente); LC (interrogativa local de objeto congruente); LI (interrogativa local de objeto incongruente).

\footnotetext{
4 Como no experimento de rastreamento ocular, as letras maiúsculas entre colchetes são as iniciais dos códigos de cada condição.
} 
ao escalpo do participante através de uma touca com aberturas posicionadas de forma a seguir o sistema internacional 10-20 estendido para distribuição dos eletrodos (cf. Figura 1).

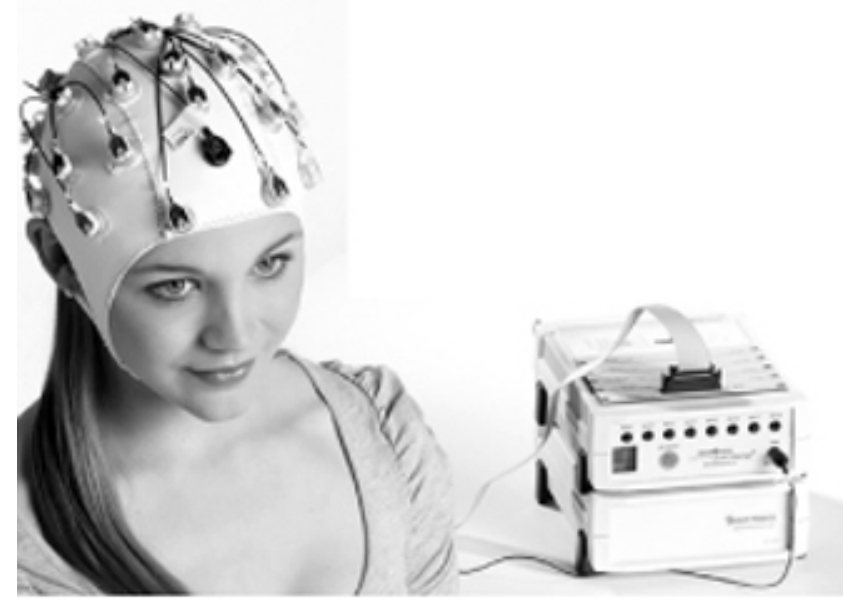

Figura 1. Participante com touca de 32 eletrodos conduzindo a eletricidade cortical para o EEG do sistema BrainVision ${ }^{\mathrm{TM}}$ (em cima o eletroencefalógrafo; em baixo o amplificador de sinais (Disponível em: http://www.brainproducts.com/ products_by_type.php?tid=1).

Enquanto o sujeito lia frases no computador (apresentadas, nesse caso, pelo E-Prime ${ }^{\mathrm{TM}}$ ), o aparelho de eletroencefalógrafo (EEG) capturava a eletricidade do córtex por meio de eletrodos fixados ao escalpo, com auxílio de uma touca especial, utilizando-se um gel condutor próprio para o procedimento.

A tarefa experimental consistiu em uma apresentação visual serial rápida do estímulo, em tempo padronizado pelo pesquisador $(250 \mathrm{~ms})$. O estímulo aparecia no centro da tela do computador, dividido em 4 segmentos, conforme o Quadro 2. Ao final de cada estímulo, surgia a pergunta "Essa frase faz sentido?". Então, o sujeito deveria julgar o que acabou de ler, escolhendo uma das respostas ("sim" ou "não"), pressionando a tecla "s" ou a tecla "l" no teclado, respectivamente, repetindo o procedimento até o fim do experimento ser anunciado na tela.

\subsubsection{Hipóteses e Previsões}

Partindo de resultados prévios de teste leitura automonitorada (OLIVEIRA; MAIA, 2010; OLIVEIRA, 2013), e do teste 1 de rastreamento ocular reportado nesse artigo (cf. seção 3.1), bem como resultados de EEG (FRANCA; GOMES, 2015; FRANÇA, 2017), decidiu-se examinar o fenômeno da ASO à luz da técnica de eletroencefalografia. Consideramos a hipótese de que efeitos de processamento também seriam encontrados na posição do sintagma nominal. Quanto a isso, duas possibilidades foram levadas em conta: as diferenças encontradas no SN após o verbo não seriam devidas à integração do sujeito, mas à reanálise da estrutura formada, um tipo de efeito garden-path (cf. OLIVEIRA, 2017) que também poderia ser encontrado em momento mais precoce. Por outro lado, se o efeito for significativo apenas (ou principalmente) na posição de objeto (neste experimento 2), como nos resultados de França e Gomes (2015) e França et al. (2017), teremos evidências de integração tardia do sujeito. Nesse caso, o parser atuaria em interrogativas-QU e em declarativas de modo semelhante: não se inicialmente não se comprometeria integralmente com a concatenação do sujeito e com a interpretação de uma possível incongruência semântica até que o constituinte no terceiro segmento (posição típica de objeto) seja integrado à estrutura em curso. Esta segunda interpretação implica a assunção de que, no nível neurobiológico, durante o curso da derivação a concatenação de objeto que acontece depois da de sujeito ainda pode causar computações tardias que afetam a integração, o que revelaria uma interessante assimetria no modus operandi do parser nos níveis psicológico e neurobiológico. Portanto, a expectativa era a de que esse efeito pudesse ser encontrado na forma de um N400 e um P600 no segmento 3, posição de objeto do verbo, especialmente na comparação $\mathrm{SC} \times \mathrm{SI}$ (estatisticamente significativa no experimento 1). Procuramos também explorar a comparação entre o pronome-QU local $\times$ movido e a relevância da integração de sintagmas-QU incongruentes semanticamente.

\subsubsection{Resultados}

Os resultados obtidos foram registrados pelo PyCorder ${ }^{\mathrm{TM}}$ na forma de períodos/contínuos de tempo contendo a atividade elétrica do sujeito participante. A partir disso, são recortados os trechos funcionais que contêm a reação do cérebro ao segmento de interesse na frase (essencialmente os mesmos que os do experimento 1). Em resumo, é feita uma sobreposição das épocas para uma mesma condição experimental, somando-as de modo a obter-se uma "grande média" (grand-average), técnica conhecida como promediação, o que permite diminuir a relação sinal-ruído ${ }^{5}$. As ondas obtidas descrevem uma trajetória de picos e descidas, característica da atividade normal do cérebro, e o ERP resultante possui

\footnotetext{
Como explica Gomes (2009:44): “O ERP geralmente apresenta valor instantâneo de 10 a 1000 vezes menor do que o EEG de fundo e por isso não pode ser visualizado antes de o sinal ser processado. Para que possa haver a visualização é necessário realizar média de várias épocas. Este procedimento se justifica por assumir-se o EEG espontâneo como um ruído branco gaussiano de média zero e os ERPs como as únicas respostas que são realmente sincronizadas com o estímulo".
} 


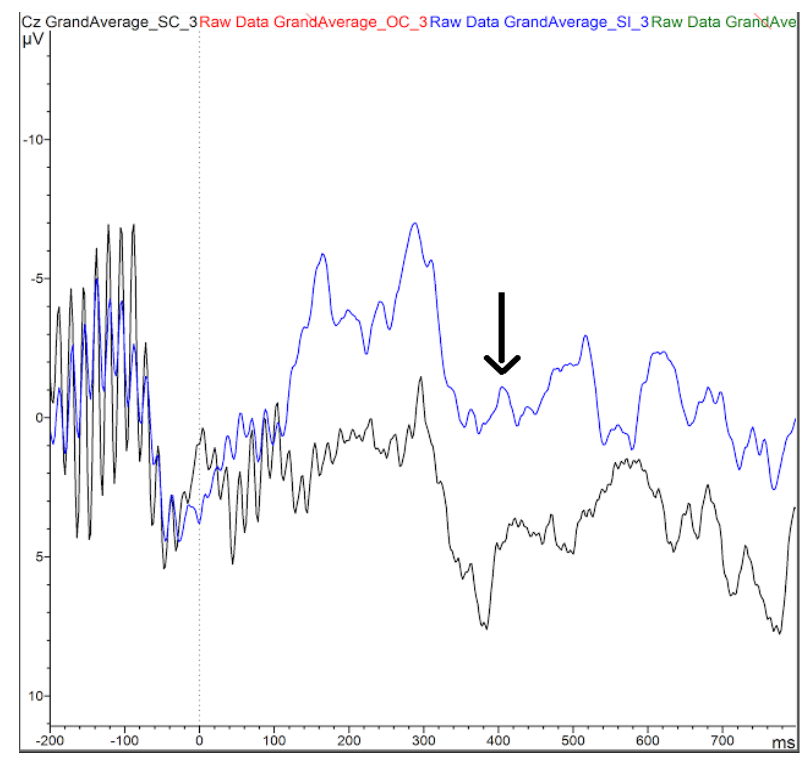

Figura 2. Comparação da resposta cortical nas condições SC $x$ SI captadas no eletrodo $\mathrm{Cz}$ relacionadas ao terceiro segmento (o turista) nas condições SC (Que bebida aqueceu o turista, em preto) versus SI (Que galáxia aqueceu o turista, em azul) Eixo vertical marca o início da estimulação. A amplitude varia de -10 a +10 microvolts. O eixo horizontal marca a latência da onda (em milissegundos). Curvas plotadas para cima têm voltagem negativa $(\mathrm{N})$. Curvas voltadas para baixo têm voltagem positiva $(P)$.

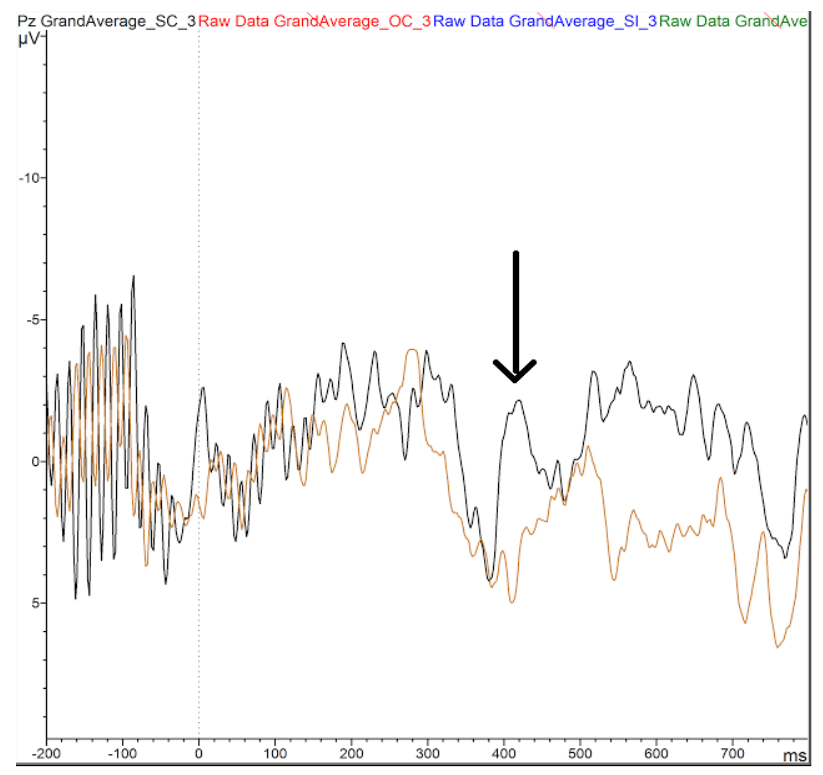

Figura 3. Comparação da resposta cortical nas condições LCXLI captadas no eletrodo Pz relacionadas, respectivamente, ao terceiro segmento (o turista) nas condições LC (O turista aqueceu que bebida no inverno?, em amarelo) versus LI ( $O$ turista aqueceu que galáxia no inverno?, em preto). O Eixo vertical marca o início da estimulação.. Eixo vertical marca o início da estimulação. A amplitude varia de -10 a +10 microvolts. O eixo horizontal marca a latência da onda (em milissegundos). Curvas plotadas para cima têm voltagem positiva $(P)$. Curvas voltadas para baixo têm voltagem negativa (N). basicamente três características: latência, a saber o tempo em milissegundos que uma onda leva para se formar; a amplitude - altura, medida em microvolts, atingida no pico da onda - e polaridade, que é exibida de modo invertido: negativo para cima e positivo para baixo. Após a promediação, (grand-average) por condição pode-se verificar se as comparações pertinentes ao estudo apresentam os ERPs esperados. Apresentamos, a seguir, as principais médias das respostas eletrocorticais, para duas comparações relevantes, cujos efeitos foram encontrados em eletrodos em região da linha média (z). A Figura 2 mostra a comparação SC x SI no eletrodo Cz: A Figura 3 mostra a comparação $\mathrm{SC} \times$ LI no eletrodo Pz:

\subsubsection{Discussão}

A comparação da Figura 2 é entre o terceiro segmento de SC (Que bebida aqueceu o turista no inverno?) e o terceiro segmento de SI (Que galáxia aqueceu o turista no inverno?).

Nessa comparação apareceu um N400 estatisticamente bem marcado (linha azul) em relação à turista (na condição incongruente: galáxia). O N400 da condição SI, indicado com a seta, é estatisticamente relevante $\left[\mathrm{F}(1,7)=4,13 ; \mathrm{p}^{*}=.003\right]$, em comparação com a outra curva (condição SC). Note-se que turista é a mesma palavra nas duas condições. O verbo também é o mesmo. Ou seja, a grande diferença de amplitude mostrando que é demandada grande energia dificultando o processamento da sentença naquele ponto da condição incongruente, diz respeito ao processamento do sujeito que só se faz por inteiro, com a entrada do objeto direto turista. Por outro lado, não há diferença entre bebida e galáxia quando medidas in loco. Isso também quer dizer que ao concatenar imediatamente sujeito e verbo, o parser não se apercebe de uma possível incongruência entre a bebida aqueceu e a galáxia aqueceu. Esse aprofundamento semântico só vai ter lugar depois da entrada do objeto.

Note-se ainda que outros trabalhos mostram resultados semelhantes (FRANÇA, et al., 2017) com declarativas. Mas esse mesmo resultado aparece aqui a partir de uma condição interrogativa. Sabemos que nas interrogativas o sintagma QU ganha muita saliência cognitiva por demandar participação iminente do interlocutor (cf. FRANÇA et al., 2004). Mesmo assim, como se pode notar pela Figura 2, os primeiros $200 \mathrm{~ms}$ anteriores ao zero e os primeiros $100 \mathrm{~ms}$, ou seja $300 \mathrm{~ms}$ anteriores, relativos exatamente ao sintagma QU não são estatisticamente diferentes apesar da implausibilidade semântica de Que galáxia aqueceu ser marcadamente maior do que a de Que turista aqueceu.

Além disso, imediatamente após ao N400, nota-se um P600 marcante, ou seja um aprofundamento da onda 
azul aos $600 \mathrm{~ms}$, mas só na condição incongruente. Isso indica ali que houve um trabalho de reanálise, causando mais esforço cognitivo para aquela sentença. Se o objeto direto incongruente já foi computado (N400), a única coisa que difere a sentença incongruente da congruente é a interpretação do sujeito à luz daquele predicado, e isso, no caso da condição incongruente, só se completa depois da inserção do sujeito. Assim a sentença incongruente apresenta um componente N400-P600.

Esse resultado é, sem dúvida, o mais expressivo. Como indicamos na seção 2.1, resultados apresentando um composto N400-P600 que mostram que o sujeito modula ondas tardias, para além das computações relativas ao objeto, foram também encontrados em França e Gomes (2015) e França et al. (2017).

Outro resultado importante é visto na Figura 3. Depreende-se um N400 estatisticamente relevante $\left[\mathrm{F}(1,7)=6,20 ; p^{*}=.001\right]$ para a leitura do segmento $o$ turista (curva preta indicada pela seta) em comparação com que galáxia na condição LI, o mesmo tipo de ERP (N400) encontrado novamente no terceiro segmento. Nesse caso, um sintagma-QU in situ (condição LI) parece oferecer maior custo, maior esforço cognitivo do que um sintagma nominal em posição canônica (condição SC). Essa maior dificuldade de processamento para interrogativas-QU in situ foi capturada também no experimento 1 , com a técnica de rastreamento ocular.

\section{Conclusões e Apontamentos}

O fenômeno Assimetria Sujeito-Objeto (ASO), alvo de pesquisas no Português Brasileiro em trabalhos com interrogativas-QU (OLIVEIRA; MAIA, 2010; OLIVEIRA, 2013; OLIVEIRA, 2017a,b), com sentenças clivadas (ALVES et al., 2015) e com declarativas (FRANÇA; GOMES, 2015; FRANÇA; CAGY; INFANTOSI, 2017) é extremamente produtivo nessa língua e começa a ser compreendido com maior profundidade à luz de recentes achados, referidos nesses artigos. Como introduzido neste artigo e também apontado por Oliveira (2017a), a literatura psicolinguística sobre a ASO no PB e em outras línguas demonstra uma clara tendência de que frases cujo constituinte relevante ao estudo desempenha função de sujeito são mais fáceis de processar do que suas contrapartes de objeto. Por outro lado, a literatura no campo da neurociência da linguagem demonstra tendência oposta: maior facilidade de processamento para o objeto em detrimento do sujeito. Diante disso, algumas interpretações colocam-se como possíveis adequações explicativas para tal discrepância: (a) os resultados obtidos com a técnica de eletroencefalografia
(EEG) poderiam ser submetidos a novas interpretações, indo ao encontro do que a literatura psicolinguística vem apontando e respeitados limites e alcances de cada campo; (b) de fato, considerando a clássica divisão proposta por Marr (1982) sobre a necessidade categórica de uma análise tripartida do objeto estudado, podemos definir claramente três níveis distintos do fenômeno aqui discutido: o nível representacional, em que a ASO se instancia em vários tipos de estruturas nas gramáticas das línguas naturais (como exemplificado na seção 2), o nível de processamento psicolinguístico, no qual o parser (assumido como serial e incrementacional) realizaria o processamento da estrutura em curso movido por uma heurística de imediaticidade, seguindo o curso top-down, gerando ASO com preferência de processamento para o sujeito, e o nível neurobiológico, em que as informações seriam processadas basicamente por meio de padrões de atividade elétrica, e as relações mais locais e primárias - como a concatenação entre verbo e complemento seriam preferidas, gerando ASO com preferência para o processamento do objeto.

Assumimos que a possibilidade (b) é mais plausível e, nesse contexto, o presente artigo trouxe uma importante contribuição, a saber, os resultados de um estudo comparativo com a utilização de diferentes técnicas (rastreamento ocular e eletroencefalografia). Comparando os resultados dos experimentos 1 e 2, percebemos uma diferença crucial entre as duas técnicas: no rastreamento ocular, os efeitos podem aparecer em momento precoce (já no segundo segmento), mas no EEG os efeitos significativos só ocorrem na posição do objeto (terceiro segmento). Um outro aspecto relevante dessa comparação diz respeito a uma semelhança: em ambos os experimentos, foi encontrada maior dificuldade de processamento para frases com sintagma-QU in situ, o que indica uma espécie de antinaturalidade dessas estruturas no PB, capturada tanto em medidas do nível psicolinguístico (mente) quanto do nível neurobiológico (cérebro).

Outras considerações sobre essa comparação poderiam ser feitas nos termos de Oliveira (2017b) e Oliveira (no prelo) quanto a uma tendência geral de que os efeitos ocorram nas frases de objeto no português e em outras línguas (cf. TROTZKE; BADER; FRAZIER, 2013), tendência associada à ideia de "terceiro fator" (CHOMSKY, 2005 e posteriores). Outras perspectivas parecem também promissoras, como o esforço conjunto dos laboratórios LAPEX e ACESIN da UFRJ na busca pelo acoplamento das duas técnicas experimentais referidas neste artigo, uma realidade cada vez menos distante à medida que avançamos no entendimento de aspectos tão pontuais e relevantes da linguagem, como o fenômeno aqui discutido. 


\section{Referências}

ALVES, M. C. S.; OLIVEIRA, T. M.; PEREIRA, L. G.; ALMEIDA, P. B. Processamento de sentenças clivadas de sujeito e objeto denotando hiponímia e contraste no português do Brasil. ReVEL, Rio de Janeiro, n. 10 (ed. esp.), p. 282-316, 2015. Disponível em: <http://www.revel.inf.br/files/8ff34075 c75611394b73615c9fecc537.pdf>. Acesso em: 28 ago. 2017.

BARILE, Wendy; MAIA, Marcus. Aspectos prosódicos do Qu in-situ no português brasileiro. ReVEL, v. 6, n. 11, ago. 2008. Disponível em: <http://www.revel.inf.br/files/artigos/revel_11_ aspectos_prosodicos_do_qu_in_situ.pdf $>$. Acesso em: 28 ago. 2017.

CEREJEIRA, J. I. G. Aquisição de Interrogativas de Sujeito e de Objeto em Português Europeu. Dissertação (Mestrado) Lisboa: UNL, 2009.

CHOMSKY, Noam. Conditions on Transformations. In: ANDERSON, S. R.; KIPARSKY, P. (Ed.). A Festschrift for Morris Halle, New York: Holt, Reinehart and Winston, Inc., 1973.

CHOMSKY, N. On Wh-Movement. In: CULICOVER, P.; WASOW, T.; AKMAJIAN, A. (Ed.). Formal Syntax. New York: Academic Press, 1977. p. 71-132.

CHOMSKY, N. Lectures on Government and Binding. The Pisa Lectures. Holland: Foris Publications. Reprint. $7^{\text {th }}$ ed. Berlim and New York: Mouton de Gruyter, 1981.

CHOMSKY, N. The Minimalist Program. Cambridge, MA: MIT Press, 1995.

CHOMSKY, N. Three Factors In Language Design. Linguistic Inquiry, v. 36, n.1, p. 1-22, winter 2005.

CLIFTON, C.; FRAZIER, L. Comprehending sentences with long-distance dependencies. In: TANENHAUS, M. K.; CARLSON, G. (Ed.). Linguistic structure in language Processing. Dordrecht: Kluwer Academic Press, 1989.

COSTA, J.; LOBO, M.; SILVA, C. Subject-Object Asymmetries in the acquisition of Portuguese relative clauses: adult vs. Children. Revista Lingua, v. 121, p. 1083-1100, 2011.

CRAIN, S.; FODOR, J. D. (1985). How can grammars help parsers? In: DOWTY, D.; KARTUNNEN, L.; ZWICKY, A. (Ed.). Natural language parsing. Cambridge: Cambridge University Press, 1985.

DE VINCENZI, Marica. Syntatic parsing strategies in Italian. Dordrecht, Holland: Kluwer Academic Publishers, 1991.

DE VINCENZI, M. Syntatic Analysis in Sentence Comprehension: Effects of Dependency Types and Grammatical Constraints. Journal of Psycholinguistic Research, v. 25, n. 1, 1996.

ELISEU, André. Sintaxe do Português. Lisboa: Editorial Caminho, 2008. (Coleção O Essencial sobre Língua Portuguesa).

FANSELOW, G.; KLIEGL, R.; SCHLESEWSKY, M. Syntactic variation in German wh questions: a rating and a training study. Linguistic Variation Yearbook, v. 5B, p. 37-63, 2005.

FRANÇA, A. I.; GOMES, J. N. A técnica de ERP: investigando a assimetria sujeito-objeto na interface sintaxe-semântica com EEG. Revista Letras de Hoje, Porto Alegre, v. 50, n. 3, p. 360-370, jul.-set. 2015.
FRAZIER, L.; FODOR, J. D. The Sausage Machine: A new two-stage parsing model. Cognition, v. 6, p. 291-326, 1978.

FRAZIER, L. Syntactic processing: Evidence from Dutch. Natural Language and Linguistic Theory, v. 5, p. 519-560, 1987.

GIBSON, Edward; THOMAS, James. Memory limitations and structural forgetting: the perception of complex ungrammatical sentences as grammatical. Language and Cognitive Processes, v. 14 , p. $225-248,1999$.

GIBSON, E. The dependency locality theory: A distancebased theory of linguistic complexity. In: MIYASHITA, Y; MARANTZ, A.; O'NEIL, W. (Ed.). Image, language, brain. Cambridge, MA: MIT Press, 2000. p. 95-126.

GIBSON, E.; DESMET, T.; GRODNER, D.; WATSON, D.; KO, $\mathrm{K}$. Reading relative clauses in English. Cognitive Linguistics, v.16, p. 313-354, 2005.

GOMES, Juliana Novo. A direcionalidade no relacionamento semântico: um estudo de ERP. Dissertação (Mestrado em Linguística) - Faculdade de Letras, Universidade Federal do Rio de Janeiro, Rio de Janeiro, 2009.

GOMES, Juliana Novo. Investigating the dissociation between N400 e P600 effects on the syntax-semantics interface: an ERP study. Tese de Doutorado em Linguística Rio de Janeiro: Faculdade de Letras, Universidade Federal do Rio de Janeiro, Rio de Janeiro, 2014.

GOUVÊA, A. C. Complexidade sintática: o processamento de orações relativas em português brasileiro e em inglês. In: MAIA, Marcus; FINGER, Ingrid [Org.]. Processamento da Linguagem: Série de Investigações em Psicolinguística/GT de Psicolinguística. Pelotas: Educat, 2005.

HOFMEISTER, P.; JAEGER, T. F, SAG, I. A.; ARNON, I.; SNIDER, N. Locality and accessibility in wh-questions. In: FEATHERSTON, S.; STERNEFELD, W. (Ed.). Roots: Linguistics in Search of its Evidential Base. Berlin: Mouton de Gruyter, 2007.

KUTAS, M.; HILLYARD, S.A. Reading senseless sentences: Brain potentials reflect semantic incongruity. Science, v. 207, p. 203-205, 1980.

KWON, N.; GORDON, P. C.; LEE, Y.; KLUENDER, R.; POLINSKY, M. Cognitive and Linguistic Factors Affecting subject/object asymmetry: an eye-tracking study of prenominal relative clauses in Korean. Language, v. 86, n. 5, p. 546-582, 2010.

LAGE, A. C.; LEMLE, M.; GESUALDI, A. R.; CAGY, M.; INFANTOSI, A. F. C. Potenciais Relacionados a Eventos (ERP) revelam o curso da derivação sintática e a dinâmica da integração entre micromódulos de cognição de linguagem. Revista Ciências \& Cognição, v. 13, n. 2, p. 03-13, 2008.

LOBO, M.; SANTOS, A. L.; SOARES-JESEL, C.; VAZ, S. Compreensão de Estruturas Clivadas na Aquisição do Português Europeu. Textos Selecionados, XXIX Encontro Nacional da Associação Portuguesa de Linguística. Porto: APL, 2014.

MAIA, Marcus; FINGER, Ingrid [Org.]. Processamento da Linguagem. Pelotas: Educat, 2005.

MAIA, M. Teoria Gramatical, Sintaxe Experimental e Processamento de Frases: explorando os efeitos do antecedente e da lacuna ativos. Revista da ABRALIN, v. 13, n. 2, p. 93-117, jul./dez. 2014a. 
MAIA, M. Efeito da lacuna preenchida e plausibilidade semântica no processamento de frases em português brasileiro. Cadernos de Letras da UFF - Dossiê: Anáfora e correferência: temas, teorias e métodos, v. 23, n. 49, p. 23-46, 2014 b.

MAIA, M.; MOURA, A.; OLIVEIRA, F. L. Ilusão Gramatical e Falibilidade Seletiva no Processamento de Lacunas Não Preenchidas em Português Brasileiro. Revista da ABRALIN, v. 13, n. 1, p. 301-324, jan./jun. 2014.

MAIA, M.; MOURA, A.; SOUZA, M. Ilhas sintáticas e plausibilidade semântica - um estudo de rastreamento ocular de frases com lacunas preenchidas em português brasileiro. Revista Scripta, Belo Horizonte, v. 20, n. 38, p. 287-305, 1ํ sem. 2016.

OLIVEIRA, F. L.; MAIA, M. Processing of Subject and Object Wh-Questions in Brazilian Portuguese. In: Papers in Psycholinguistics: Proceedings of First International Psycholinguistics Congress. Rio de Janeiro: Imprinta, 2010.

OLIVEIRA, Fernando Lúcio de. O Processamento da Assimetria Sujeito-Objeto em Construções do Tipo QU no Português Brasileiro: Interrogativas e Relativas. Dissertação (Mestrado) - Universidade Federal do Rio de Janeiro, Rio de Janeiro, 2013.

OLIVEIRA, F. L. O processamento da assimetria sujeito-objeto e a hipótese da assimetria como terceiro fator. Tese (Doutorado)
- Faculdade de Letras, Universidade Federal do Rio de Janeiro, Rio de Janeiro, 2017a.

OLIVEIRA, F. L. O Efeito da Lacuna Preenchida na posição de sujeito no português brasileiro. Soletras, PPLIN/UERJ, p. $89-104,2017 \mathrm{~b}$.

OLIVEIRA, F. L. Sobre a noção de Terceiro Fator de Noam Chomsky. Seminário “A UFRJ faz 100 anos”. Comunicação oral, 2017.

QUAREZEMIN, S. Assimetria Sujeito-Objeto Focalizados nas sentenças clivadas e pseudoclivadas. Revista Veredas, v. 18, n. 1, p. 60-78, 2014.

STOWE, L. Parsing wh-constructions: evidence for on-line gap location. Language and Cognitive Processes, v. 1, p. 227-463, 1986.

TRAXLER, M. J.; MORRIS, R. K.; SEELY, R. E. Processing Subject and Object Relative Clauses: Evidence from Eye Movements. Journal of Memory and Language, v. 47, p. 69-90, 2002.

Recebido: 04/11/2017

Aprovado: 16/01/2018

Contato:

Aniela Improta França <aniela@gmail.com> 